\title{
LESÃO DE TECIDOS MOLES CAUSADA POR ARMA BRANCA - REVISÃO DE LITERATURA
}

\section{SOFT TISSUE INJURY CAUSED BY STEEL - LITERATURE REVIEW}

\author{
Rodolfo Freitas Dantas* \\ Mikaele Aryelle Pessoa Dias** \\ Manoel de Oliveira Dantas Filho*** \\ Eduardo Dias Ribeiro $\ldots$ \\ Gilka Soares Sampaio de Andrade ${ }^{* * * *}$
}

\section{RESUMO}

Os ferimentos faciais variam amplamente na sua apresentação e complexidade, merecendo uma abordagem adequada, haja vista que os insucessos podem resultar em alterações estético-funcionais. Aspectos como tempo de exposição do ferimento, anestesia, fios de suturas e profilaxia antitetânica constituem pontos controversos. Este trabalho abrange uma revisão sobre as lesões de tecidos moles causadas por arma branca. São também enfatizadas informações sobre a classificação, diagnósticos e tratamento, com dados extraídos de literatura recente e relatos de casos.

DESCRITORES: Ferimentos e traumatismos; Técnicas de sutura; Cirurgia maxilofacial.

\section{ABSTRACT}

The facial injuries vary widely in presentation and complex, deserving an appropriate approach, given that failures may result in aesthetic and functional changes. Aspects such as exposure time of the injury, anesthesia, sutures and tetanus prophylaxis are controversial. The work included a review of the soft tissue injuries caused by steel, and emphasized information about the classification, diagnosis and treatment, with data extracted from recent literature and case report.

DESCRIPTORS: Wounds and injuries; Suture techniques; Oral surgery

* Acadêmico do Curso de Odontologia pelo Centro Universitário de João Pessoa, UNIPÊ-PB

** Acadêmica do Curso de Odontologia pela Universidade Estadual da Paraíba - UEPB

*** Residente em Cirurgia e Traumatologia Bucomaxilofacial pelo Hospital Universitário Evangélico de Curitiba - HUEC-PR

**** Professor Assistente das disciplinas de Cirurgia e Estomatologia do UNIPÊ-PB

***** Professora Doutora da disciplina de Estomatologia do UNIPÊ-PB 
INTRODUÇÃO E REVISÃO DE LITERATURA

Os ferimentos dos tecidos moles da face assumem um papel de destaque no atendimento a pacientes politraumatizados nas emergências, já que essas lesões podem comprometer definitivamente a vida do ser humano, pois, quando mal abordadas, deixam sequelas, marginalizando o indivíduo do convívio social, resultando, muitas vezes, em incapacidade de trabaIho, condenando-o ao segregamento econômico. Ferimentos são lesões resultantes de agressão sobre as partes moles, provocadas por um agente traumático, acarretando dano tecidual, podendo ser superficiais ou profundos. Em geral, causam dor e sangramento de intensidades variáveis, com risco de infecção local ${ }^{1}$.

É importante que o Cirurgião e Traumatologista Bucomaxilofacial conheça os princípios básicos de tratamento dessas lesões, para obter o melhor resultado possível, minimizando as sequelas estéticas e funcionais. O presente estudo objetiva apresentar um relato de caso clínico sobre lesões de tecidos moles causadas por arma branca e revisão de literatura acerca da classificação, diagnóstico e tratamento dessa fratura.

Outra condição a ser avaliada é a imunização do paciente contra o tétano. Este é causado por um bacilo Gram-positivo, o Clostridium tetani, comumente encontrado no solo e em fezes de animais. Fatores, como etiologia das feridas, grau de contaminação do ferimento, tempo de vacinação do indivíduo devem ser considerados. Se este recebeu as três doses da vacina e for ferido, não necessita de nenhuma medicação antitetânica².

É de suma importância a correta abordagem dos ferimentos de face. È essencial, para um resultado satisfatório a médio e longo prazo, a observância de princípios básicos como remoção de tecidos inviáveis e a regularização das bordas do ferimento, diminuindo, respectivamente, o risco de infecção e a possibilidade de cicatrizes sem esquecer-se das necroses teciduais; suturas por planos a fim de evitar espaços mortos e, com isso, a possibilidade de proliferação bacteriana à custa da formação de hematomas, além de suturas sem tensão e sobre tecido ósseo íntegro com o intuito maior de evitar deiscências das mesmas ${ }^{3}$.

Segundo Taher ${ }^{4}$ (1998), os ferimentos abrasivos são resultado do contato brusco da pele com superfícies planas ou ásperas, que acarreta, geralmente, a remoção da camada mais superficial desse tecido. A lesão apresenta superfícies irregulares, margens mal definidas e, normalmente, presença de corpos estranhos. A exposição da camada conjuntiva e de fibras nervosas proporciona uma ferida com sensibilidade exacerbada, porém com prognóstico favorável.

As feridas puntiformes são causadas por instrumentos perfurantes, de aspecto pontiagudo, com diâmetro geralmente uniforme, por exemplo: prego e furador de gelo. Apresenta-se como uma lesão em forma de ponto e pouco sangrante, que, geralmente, não proporciona grandes danos superficiais, porém, em profundidade, pode atingir órgãos vitais. Ferimentos cortantes são resultado do deslizamento de objeto de superfície afiada sobre os tecidos, como facas, navalhas e lâminas. Geralmente, são profundos e apresentam bordas bem lineares.

As feridas promovidas por instrumentos corto-contundentes, ou seja, que apresentam um mecanismo cortante e contundente ao mesmo tempo, como foice, facão e machado 5 .

A lesão contusa apresenta margens irregulares, sinuosas e estreladas, por serem produzidas por instrumentos rombos, através de forças de compressão, tração, percussão e arrastamento. A ação de instrumentos como facas e punhais, que representam meios mistos, resultam em feridas perfuro-cortantes. Possuem aspecto linear em forma de fenda. As feridas pérfuro-contusas ocorrem, quando o mecanismo de ação perfura e contunde ao mesmo tempo, como as ocasionadas por projéteis de arma de fogo. O aspecto dessas lesões é bastante variado, dependendo do calibre da arma, distância do disparo, ou, ainda, se representa o orifício de entrada ou de saída do projétil ${ }^{5}$.

Pode-se evidenciar uma multiplicidade de golpes no mesmo local, proferidos com
DANTAS RF

DIAS MAP

DANTAS-FILHO MO

RIBEIRO ED

ANDRADE GSS

LESÃO DE

TECIDOS MOLES

CAUSADA POR

ARMA BRANCA

- REVISÃO DE

LITERATURA
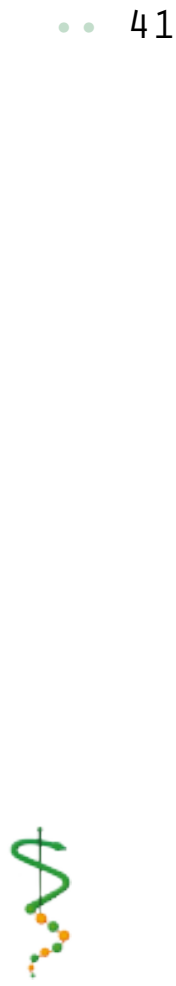

REV. ODONTOL.

UnIV. CID. São

PAULO

2013; 25(1): 40-6 JAN-ABR 
DANTAS RF

DIAS MAP

DANTAS-FILHO MO

RIBEIRO ED

ANDRADE GSS

LESÃO DE

TECIDOS MOLES

CAUSADA POR

ARMA BRANCA

- REVISÃO DE LITERATURA

REV, ODONTOL. UNIV, CID, SÃO

PAULO

2013; 25(1): 40-6, grande mobilidade que provoca laceração tecidual, comprometendo os planos subjacentes, músculos, vasos, tendões, nervos e, até, os tecidos duros ${ }^{2}$.

Serão discutidos, neste trabalho, com embasamento de literaturas atuais e relato de casos, aspectos como classificação dos ferimentos e condutas a serem tomadas, enfatizando a escolha da anestesia e dos fios de sutura bem como manobras que objetivam melhores resultados estético-funcionais.

\section{RELATO DE CASO}

\section{Condutas no tratamento dos ferimen- tos faciais \\ Escolha da anestesia}

Os ferimentos faciais podem ser tratados sob anestesia local ou geral. A anestesia local é utilizada na maioria dos casos, sendo a droga de primeira escolha o cloridrato de lidocaína na concentração de $2 \%$, sem ou com vasoconstritor, que geralmente é a epinefrina. A dosagem de lidocaína não deve ultrapassar $4,4 \mathrm{mg} / \mathrm{Kg}$ nas soluções sem vasoconstritor e $7 \mathrm{mg} / \mathrm{Kg}$ nas soluções com vasoconstritor. O uso de vasoconstritores objetiva a diminuir o sangramento, retardar a absorção e prolongar o efeito anestésico, sendo as técnicas de bloqueio regional e infiltrativa terminal as mais adotadas. A utilização do óxido nitroso em sedação consciente surge como uma alternativa viável para pacientes infantes, pouco cooperativos, bem como psiquiátricos. Uma indução rápida e fácil recuperação, associadas a um efeito analgésico e ansiolítico eficaz, proporcionam um ambiente seguro para procedimentos sucintos, resguardando a anestesia geral para lesões ${ }^{3}$.

\section{Limpeza do ferimento}

A limpeza meticulosa do ferimento é fundamental para a obtenção de boa cicatrização e prevenção de infecções. O ferimento deve ser submetido à lavagem copiosa com soro fisiológico a $0,9 \%$ em forma de jato, removendo coágulos e corpos estranhos. A utilização de agentes antissépticos, como água oxigenada, deve ser evitada, devido aos danos teciduais em decorrência de sua ação cáustica. A poliviniliodopirrolidona (polvidine) fica reservada a feridas infectadas e absces$\operatorname{sos}^{1}$.

\section{Hemostasia}

A hemostasia deve ser eficiente, prevenindo a formação de hematomas e, consequentemente, espaço morto. O melhor e mais rápido método de hemostasia é a eletrocoagulação. Cuidado deve ser tomado com a intensidade da corrente para que a ponta não atinja a pele. Contudo, em vasos com diâmetro acima de $2 \mathrm{~mm}$, pode ser necessária a ligadura, preferencialmente fio vycril 2-06.

\section{Debridamento}

Trata-se da remoção de tecidos inviáveis e a regularização das bordas do ferimento, diminuindo, respectivamente, o risco de infecção e a possibilidade de cicatrizes deformantes. As ressecções de tecidos macerados ou necróticos devem ser realizadas com bisturi ou tesouras bastante afiadas ${ }^{7}$.

\section{Fios de Sutura}

Nas suturas de face, deve-se utilizar fios que promovam boa aproximação das bordas da ferida, menores marcas na pele e menor reação do tipo corpo estranho, assim como agulhas menos traumáticas possíveis. O fio de sutura deve, preferencialmente, causar irritação mínima aos tecidos, determinando uma resposta inflamatória de baixa intensidade e curta duração ${ }^{8}$. Os fios indicados no tratamento dos ferimentos faciais são os de poliglactina $910($ Vicryl $\mathbb{R} /$ Ethicon - Johnson \& Johnson e Monocryl $\mathbb{R} /$ Ethicon - Johnson \& Johnson) e nylon (Mononylon®/Ethicon Johnson \& Johnson).

\section{Suturas}

A síntese dos tecidos deve ser realizada com material delicado e adequado. Os tecidos devem ser aproximados por planos anatômicos, impedindo a formação de espaço morto. Essa manobra minimiza as tensões superficiais e restabelece a posição original das camadas, além de favorecer a regeneração das fibras nervosas lesadas. A aproximação dos planos profundos (muscular e subcutâneo) é indispensável, pois evita a formação de espaços mortos, além de facilitar o retorno à função dos músculos da expressão facial, importantes no equilíbrio e na mímica ${ }^{9}$.

Nos ferimentos acidentais, é preferível 
a sutura por pontos simples e separados, utilizando-se pontos simples invertidos nos planos profundos, a fim de se evitar a tensão da sutura final da pele. Para os planos profundos, dá-se preferência a fios absorvíveis, como o Monocryl@ 4-0, enquanto que, na pele, utilizam-se fios inabsorvíveis, como o Mononylon $®$ 5-0 e 6-0. Os pontos de suturas devem ser realizados próximos às bordas da ferida e não devem causar tensão tecidual, que pode resultar em isquemia e cicatrizes perpendiculares à ferida, por necrose tissular na área contida pelo fio $^{10}$.

Em ferimentos extensos e irregulares, o ponto inicial deve ser realizado no centro do ferimento, e os demais dividindo os espaços restantes simetricamente, com o objetivo de evitar a dobra lateral da pele ("orelha de pele"). Por vezes, faz-se necessária a utilização de enxertos e rotação de retalhos em situações nas quais há perda de tecido. Em ferimentos transfixantes que atingem pele e mucosa, a sutura deve ter início nessa última e seguir em direção à pele'.

Ferimentos em mucosa bucal podem ser suturados com fios absorvíveis, tipo Monocryl ${ }^{\circledR}$ 4-0. A utilização do octilcianoacrilato-2 em reparação de lacerações superficiais em pele surge como uma alternativa às suturas convencionais. Mínimo índice de infecção e de reação tecidual, associado a resultados estético-funcionais satisfatórios, faz desse adesivo um material viável para síntese externa de feridas ${ }^{11}$

\section{Curativos}

A utilização de curativos protege o ferimento contra corpos estranhos e raios solares. Dá-se preferência a adesivos an-

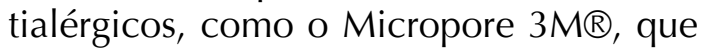
auxilia no fechamento da ferida e diminui as forças de tensão, exercidas pelas fibras musculares. O paciente deve ser instruído a utilizar filtro solar na área do ferimento, a fim de protegê-la da exposição aos raios solares por, aproximadamente, 90 dias $^{12}$.

\section{I SCUSSÃ 0}

Embora o aspecto dos ferimentos faciais seja geralmente deformante, devemos considerar o paciente como um todo, respeitando os princípios do atendimento inicial ao paciente traumatizado, priorizando as lesões que possam causar risco de vida a ele. Estabelecidas as prioridades, deve-se avaliar a extensão da lesão, agente etiológico, estado geral do paciente, além de identificar eventuais fraturas faciais. Antes de instituir uma terapêutica clínico-cirúrgica dos ferimentos faciais, deve-se garantir que o paciente não apresente lesões que ponham sua vida em risco ${ }^{13}$.

Estruturas anatômicas importantes devem ser avaliadas nos traumatismos faciais. Ferimentos profundos na região parotídea-massetérica merecem o exame do ducto da glândula parótida e do nervo facial. Em lesões aparentemente inofensivas, como as abrasões e escoriações, também se faz importante a lavagem copiosa com soro fisiológico, minimizando o risco

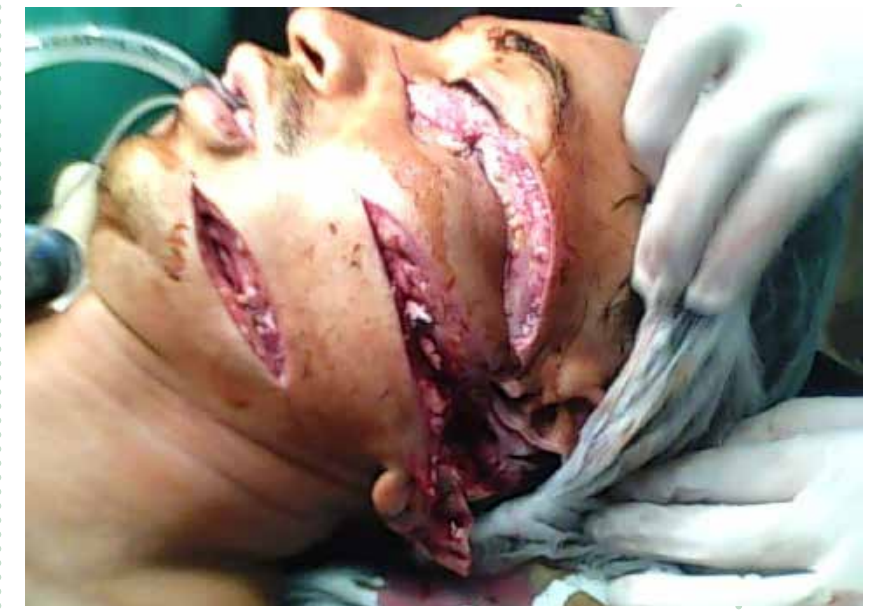

Figuras. 1 e 2 - Lesão cortante oriunda de agressão por arma branca (foice). Observar ferimento com bordas bem definidas.

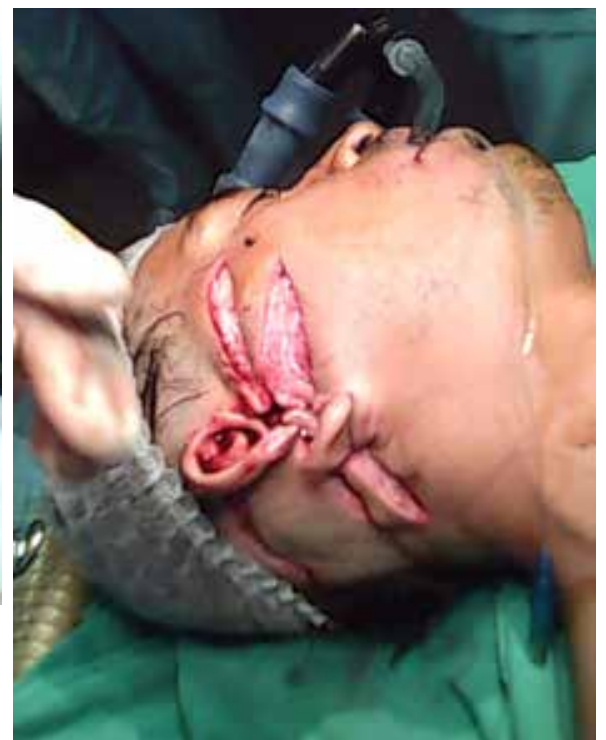

DANTAS RF

DIAS MAP

DANTAS-FILHO MO

RIBEIRO ED

ANDRADE GSS

LESÃO DE

TECIDOS MOLES

CAUSADA POR

ARMA BRANCA

- REVISÃo de

LITERATURA
ReV. OdOnTOL.

Univ. Cid. São

PAULO

$2013 ; 25(1): 40-6$ JAN-ABR 

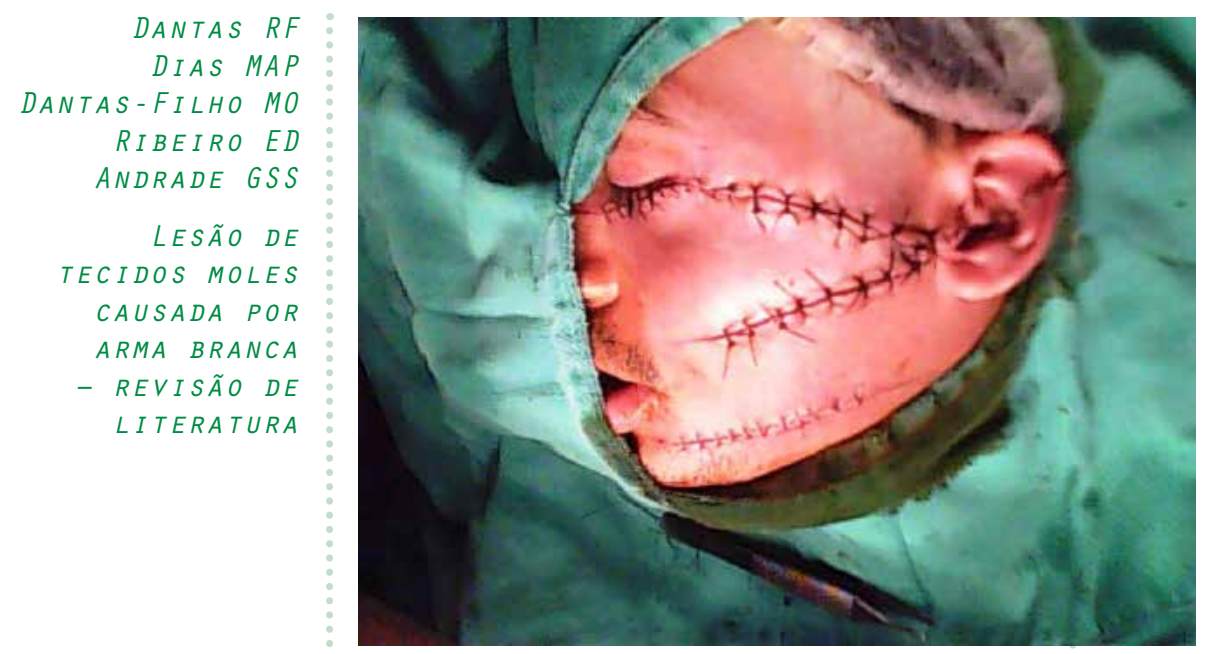

Figuras. 3 e 4 - Extensão das lesões, após síntése tecidual Lado direito e esquerdo respectivamente.

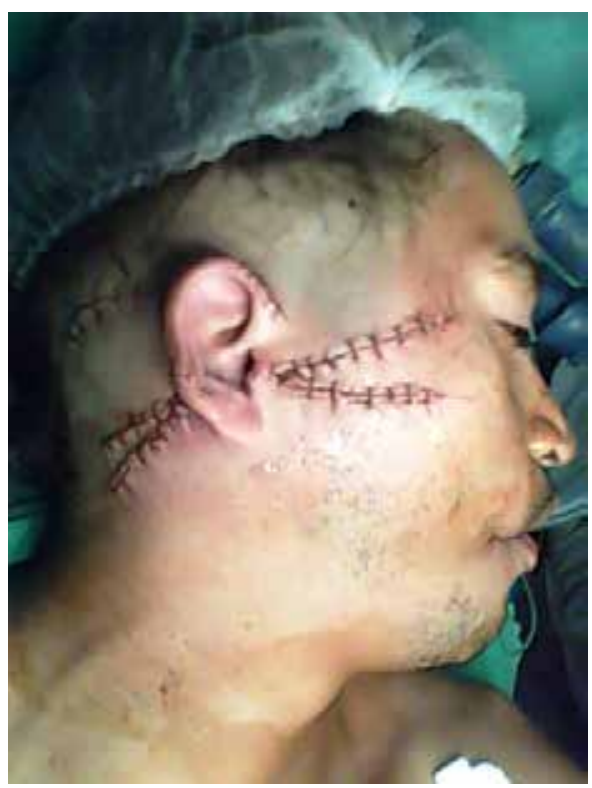

de infecção e, consequentemente, o retardo do processo de cicatrização. Já em lesões puntiformes, como, por exemplo, penetrações de instrumentos perfurantes na região de palato, principalmente em crianças, por vezes não é necessária a realização de suturas ${ }^{14}$.

É controversa a sutura de feridas com grande tempo de exposição, visto o risco de infecção destas. Sabendo-se que a face é uma região altamente vascularizada e cicatrizes não estéticas podem alterar o convívio social do paciente, somos de opinião de que a sutura desses ferimentos proporciona resultados satisfatórios em até 24 horas após a lesão. O tratamento dos ferimentos causados por mordedura animal é bastante discutido, haja vista que existe uma controvérsia na literatura quanto ao fechamento ou não dessas feridas. Somos de opinião de que o fechamento primário dessas lesões é a melhor opção. É importante a lavagem exaustiva com solução fisiológica e antissépticos, como a clorexidina, acompanhada de escovação copiosa, induzindo ao sangramento, principalmente das bordas da ferida ${ }^{15}$.

Os ferimentos faciais variam amplamente na sua apresentação e complexidade, sendo tratados de acordo com sua extensão, profundidade, grau de contaminação, agente etiológico e tempo do trauma. Esses ferimentos devem ser tratados o mais rápido possível. Resultados estéticos insatisfatórios e infecção estão relaciona- dos às feridas com maior tempo de exposição dos tecidos. Outra condição a ser avaliada é a imunização do paciente contra o tétano. Este é causado por um bacilo Gram-positivo, o Clostridium tetani, comumente encontrado no solo e em fezes de animais. Fatores como etiologia das feridas, grau de contaminação do ferimento, tempo de vacinação do indivíduo devem ser considerados. Se o indivíduo recebeu as três doses da vacina e for ferido, não necessita de nenhuma medicação antitetânica. Contudo, transcorridos 5 anos ou mais da última dose, é conveniente administrar um reforço da vacina antitetânica (VAT) $(0,5 \mathrm{~mL}$ IM). Caso o paciente não tenha sido vacinado, deve-se administrar o soro antitetânico (SAT) (10.000UI - adulto e 5.000UI - criança) após teste de sensibilidade negativa, ou, se possível, administrar a imunoglobulina humana antitetânica, menos alergênica (250UI - adulto e 125 UI - criança), e iniciar a vacinação do paciente ${ }^{2}$.

A colocação de drenos, por vezes, é o procedimento correto, juntamente com antibioticoterapia maciça e profilaxia anti-rábica. Aspecto que deve ser considerado é a observância de detalhes que contribuem para o melhor resultado estético-funcional dos ferimentos faciais, como, por exemplo, a regularização de bordas, a hemostasia eficaz, sutura por planos anatômicos bem como fios finos e material delicado ${ }^{6}$. 
Quanto à anestesia, esta deve ser suficiente para não ocasionar dor durante o procedimento; entretanto, a injeção de grande quantidade de anestésico deve ser evitada, pois resulta em distorções nas áreas a serem suturadas. Uma opção seria a anestesia por bloqueio regional. Outra situação que deve ser evitada é a infiltração demasiada de anestésicos com vasoconstrictores nas regiões de cartilagem, como nariz e orelha, devido ao risco de necrose $^{15}$.

\section{CONCLUSÕES}

Os ferimentos faciais variam amplamente na sua apresentação e complexidade, sendo tratados de acordo com sua extensão, profundidade, grau de contaminação, agente etiológico e tempo do trauma, devendo ser abordados de forma especial, a fim de restituir a função e estética do paciente. Os avanços na tecnologia e conhecimentos dos processos de reparação e cicatrização tecidual contribuíram para o desenvolvimento de técnicas que proporcionam bons resultados.

Torna-se evidente, então, que o Cirurgião Buco-Maxilo-Facial conheça os princípios básicos de tratamento dessas lesões, para obter o melhor resultado possível, minimizando as sequelas estéticas e funcionais. É o somatório de detalhes que determina o sucesso no tratamento desses ferimentos, devolvendo, assim, o paciente a seu convívio social.
DANTAS RF

DIAS MAP

DANTAS-FILHO MO

RIBEIRO ED

ANDRADE GSS

LESÃO DE

TECIDOS MOLES

CAUSADA POR

ARMA BRANCA

- REVISÃo de

LITERATURA

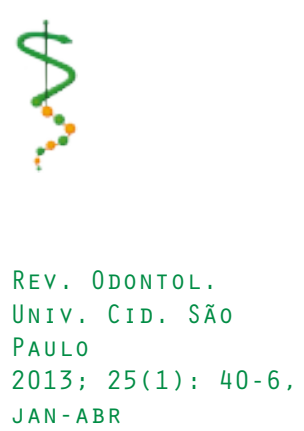


DANTAS RF

DIAS MAP

DANTAS-FILHO MO

RIBEIRO ED

ANDRADE GSS

LESÃO DE

TECIDOS MOLES

CAUSADA POR

ARMA BRANCA

- REVISÃO DE LITERATURA

\section{REFERÊNCIAS}

1. Peterson LJ, Ellis E, Hupp JR, Tucker MR. Cirurgia oral e maxilofacial contemporânea. 3 ed. Rio de Janeiro: Guanabara Koogan; 2000.

2. Tenório EB, Bráz M. A intervenção do enfermeiro como diferencial de qualidade no tratamento de feridas. Rev Bras Home Care 2002 fev.;10(2):4.

3. Malamed Stanley F. Manual de anestesia local. Rio de Janeiro: Elsevier;

4. Taher AA. Management of weapon injuries to the craniofacial skeleton. J Craniofac Surg 1998 Jul;9(4):371-82.

5. Azevedo R CJB, Gonzalez A,. Traumatismo facial por agressão com arma branca $\mathbf{\square}$ relato de um caso clínico. Rev Odonto Ciênc 2003 jan./mar.;18(39):13-6.

6. Barros JJ, Souza LCM. Traumatismo buco-maxilo-facial. São Paulo: Roca; 2000.

7. Neville BW, Damm DD, Allen CM, Bouquot JE. Patologia oral \& maxilofacial. 2 ed. Rio de Janeiro: Guanabara Koogan; 2004.

8. Cuffari L. Considerações gerais em odontologia dos fios de sutura. JBC J Bras Odontol Clín 1997 jan./fev.;1(1):43-7.

9. Singer AJ, Gulla J, Hein M, Marchini S, Chale S, Arora BP. Single-layer versus double-layer closure of facial lacerations: a randomized controlled trial. Plast Reconstr Surg 2005 Aug;116(2):363-8; discussion 9-70.

10. Fonseca RJ. Oral and maxillofacial surgery. Philadelphia: W. B. Saunders; 2000.

11. Fatureto MC, Teixeira VPA. Propriedades dos fios de sutura. In: Hering FLO, editor. Bases técnicas e teóricas de fios e suturas. São Paulo: Roca; 1993. p. 23-8.

12. Bsachion MM, Nakatani AYK. Tratamento de feridas. Goiás: Faculdade de Enfermagem - Universidade Federal de Goiás; s.d.

13. American CoS. Advanced trauma life support Chicago: ATLS; 2004; Available from: http://www.facs.org/trauma/atls/index.html.

14. Miloro M. Princípios de cirurgia bucomaxilofacial de Peterson. 2 ed. São Paulo: Santos; 2009.

15. Motamedi $\mathrm{MH}$, Behnia $\mathrm{H}$. Experience with regional flaps in the comprehensive treatment of maxillofacial soft-tissue injuries in war victims. J Craniomaxillofac Surg 1999 Aug;27(4):256-65.

Recebido em: 10/11/2011

Aceito em: 09/04/2012
REV. ODONTOL.

UNIV, CID, SÃO

PAULO

2013; 25(1): 40-6 